\title{
Correlação das Leishmanioses humanas com o bioma cerrado no Estado de Goiás
}

\author{
Hidasi Filho ${ }^{1,3}$ \\ Marco-Túlio Garcia-Zapata ${ }^{2 *}$
}

\begin{abstract}
RESUMO - Nas formações florestais existentes no cerrado de Goiás destacam-se as matas ciliares, que exibem as características ecológicas necessárias para o desenvolvimento das populações de flebotomíneos. Em Goiás a existência da Leishmaniose Tegumentar foi comprovada por meio da descrição de casos autóctones desde 1965, por Barbosa e colaboradores. A partir de então, com o desbravamento de novas regiões, o número de doentes vem aumentando progressivamente. Este artigo visa descrever o perfil percorrido pela doença no cerrado goiano.
\end{abstract}

Palavras-chave: leishmanioses, bio-ecologia, cerrado.

\section{Human Leishmaniasis correlation with savannah of Goias}

\begin{abstract}
In the existent forest formations in the savannah of Goias stands out ciliary forest, type that exhibits the necessary ecological characteristics for the development of the phlebotomines populations. In Goias the existence of American Tegumentar Leishmaniasis was proven through the description of autochthonous cases since 1965 for Barbosa e cols. Ever since, with the grubbed of new areas, the number of patients is increasing progressively. This article aims to describe the ecological profile by the disease in the goianan savannah.
\end{abstract}

Key words: leishmaniasis, bio-ecology, savannah.

${ }^{1}$ UEG (Universidade Estadual GO); ${ }^{2}$ IPTSP (Instituto de Patologia Tropical e Saúde Pública)UFG (Universidade Federal GO) \& ${ }^{3}$ UCG (Universidade Católica GO).

mctulian1@ hotmail.com; zapata@iptsp.ufg.br 
As leishmanioses se estendem em nosso país por extensas áreas das regiões Norte, Nordeste, Sudeste e Centro-Oeste. Enquanto a forma tegumentar é mais amplamente distribuída por quase todos os estados da nação, a forma visceral apresenta distribuição mais restrita às áreas do nordeste e sudeste do País (Ministério da Saúde, 2000). A região Centro-Oeste é considerada área de transição por vários aspectos: ao norte encontra-se a região equatorial, a noroeste a região semi-árida e ao sul a região sub-tropical. A presença de chapadas com planaltos e vales de fundo chato sugerem a caracterização da manutenção da fauna de flebótomos das leishmanioses em Goiás.

O conhecimento da fitoecologia (vegetais do ambiente) e de dados da pedologia, ou seja, do estudo do solo (Moniz,1972) de Goiás evidenciam aspectos importantes do meio ambiente que se relacionam com a doença. A inexistência de dados sobre reservatórios silvestres e domésticos em Goiás tende a dificultar a atuação ao nível profilático (Nascimento, 1986). Portanto, o conhecimento de aspectos ambientais e fitofisionômicos (fitogeográficos) das áreas endêmicas tem dado importante contribuição ao conhecimento ecológico da fauna de flebotomíneos.

Grande parte da região Centro-Oeste concentra-se no bioma cerrado. De acordo com Masutomo e cols. (1994) e Ribeiro \& Walter (1998), o Cerrado brasileiro caracteriza-se pela presença de inverno seco e verão chuvoso, um clima classificado como Aw de Köppen (tropical chuvoso). Possui média de precipitação de 1500 $\mathrm{mm}$, variando de 750 a $2000 \mathrm{~mm}$. O contraste entre as regiões mais baixas (inferiores a 300 m), as longas chapadas entre 900 e 1600 m e a extensa distribuição em latitude confere ao Cerrado uma diversificação térmica bastante grande.

Ribeiro e Walter (1998) apresentaram uma classificação fitofisionômica do bioma cerrado com base nas formas e nos tipos de vegetação. Entende-se por fisionomia a forma de vegetação; a fitofisionomia inclui o ambiente, a estrutura, as formas de crescimento (árvores, arbustos) e as mudanças estacionais (sempreverde, semi-decídua) predominantes na vegetação. A estrutura, por sua vez, referese à disposição, organização e arranjo dos indivíduos na comunidade, tanto em altura (estrutura vertical) quanto em densidade (estrutura horizontal). Esses mesmos pesquisadores descreveram onze tipos fitofisionômicos gerais, enquadrados em três formas de vegetação que são as Formações florestais, Formações savânicas e Formações campestres, descritas a seguir.

a) Formações florestais: englobam tipos de vegetação com predominância de espécies arbóreas e formação de dossel (Formação de dossel, relativo a florestal. É a linha imaginária que liga os pontos extremos dos indivíduos componentes de 
um maciço florestal, assinalando, desse modo, as diferentes alturas da vegetação dominante). A mata ciliar e a mata de galeria são fisionomias associadas aos cursos de água e a mata seca e o cerradão ocorrem nos interflúvios.

Nas formações florestais existentes no ambiente silvestre de Goiás, destacase o principal tipo de vegetação que exibe as características ecológicas necessárias para o desenvolvimento das populações de flebotomíneos. As matas de galeria ou ciliar que ocorrem nas proximidades dos vales fluviais por todo o Estado, onde árvores são de médio porte; mais fechadas, quando circunscritas aos rios, criam um microclima ideal para a manutenção dessas populações (Nascimento, 1986).

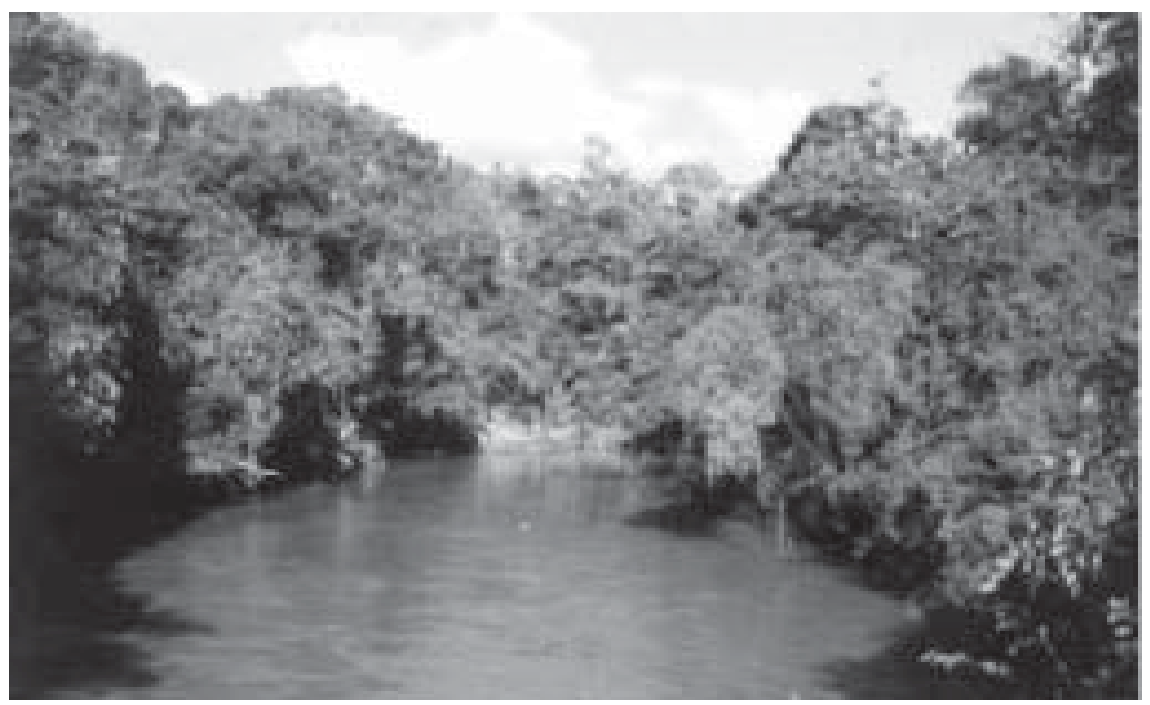

Figura 1 - Formação Florestal, tipo Mata ciliar (Fazenda São Sebastião da Garganta) Microclima ideal de Flebotomíneos \& Leishmanias. Rio dos Bois - Silvânia - GO. Hidasi, 2002.

Na área de nosso estudo, nos arredores da Capital de Goiás, em Silvânia observamos florestas ciliares que têm os requisitos para a vida dos flebotomíneos (Santos et al, 2001). Assim temos observado, por exemplo, um microclima ideal para os flebótomos nas margens do Rio dos Bois, no município de Silvânia, a menos de cem kilômetros de Goiânia, (Fig. 1).

b) Formações savânicas: englobam quatro tipos fitofisionômicos principais: o cerrado sentido restrito, o parque de cerrado, o palmeiral e a vereda. $\mathrm{O}$ cerrado 
sentido restrito caracteriza-se pela presença dos estratos arbóreos e arbustivoherbáceos definidos, com árvores distribuídas aleatoriamente sobre o terreno em diferentes densidades. No parque de cerrado a ocorrência de árvores é concentrada em locais específicos do terreno (Fig. 2). No palmeiral, há a presença marcante de uma determinada espécie de palmeira arbórea e as árvores de outras espécies não têm destaque. Já a vereda também se caracteriza pela presença de uma única espécie de palmeira, o buriti, mas ocorre em menor densidade que em um palmeiral.

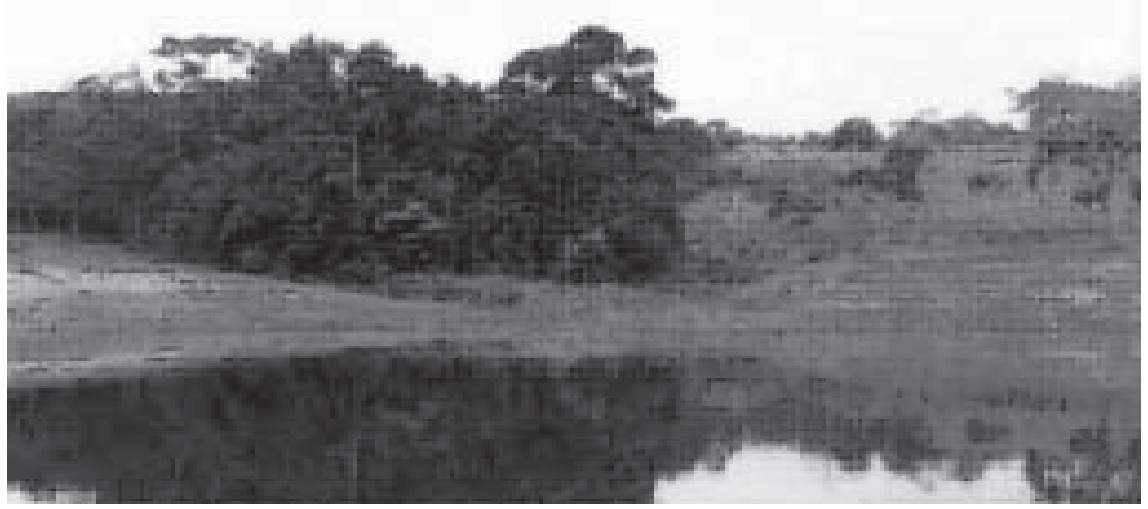

Figura 2 - Formação savânica - Parque de cerrado - Fazenda Alegria - Silvânia - GO. Hidasi, 2002.

Na formação savânica, tem-se observado diversos momentos, quando os flebotomíneos migram de um local para outro, na procura de seu habitat apropriado, sua presença em tocas e buracos, esconderijos de animais silvestres e sem ventania. (Santos,2002 - comunicação pessoal).

c) Formações campestres: englobam três tipos fitofisionômicos principais: o campo sujo, o campo rupestre e o campo limpo. O campo sujo caracteriza-se pela presença marcante de arbustos e subarbustos entremeados no estrato herbáceo. O campo rupestre possui estrutura similar ao campo sujo, diferenciando-se pelo 
substrato, composto por afloramentos de rocha, e também pela composição florística, que inclui muito endemismo. No campo limpo a presença de arbustos e subarbustos é insignificante. Na figura 3 pode-se observar um exemplo de formação campestre, modalidade campo sujo. Os Flebotomíneos encontram as mesmas condições de habitat que nas formações savânicas.

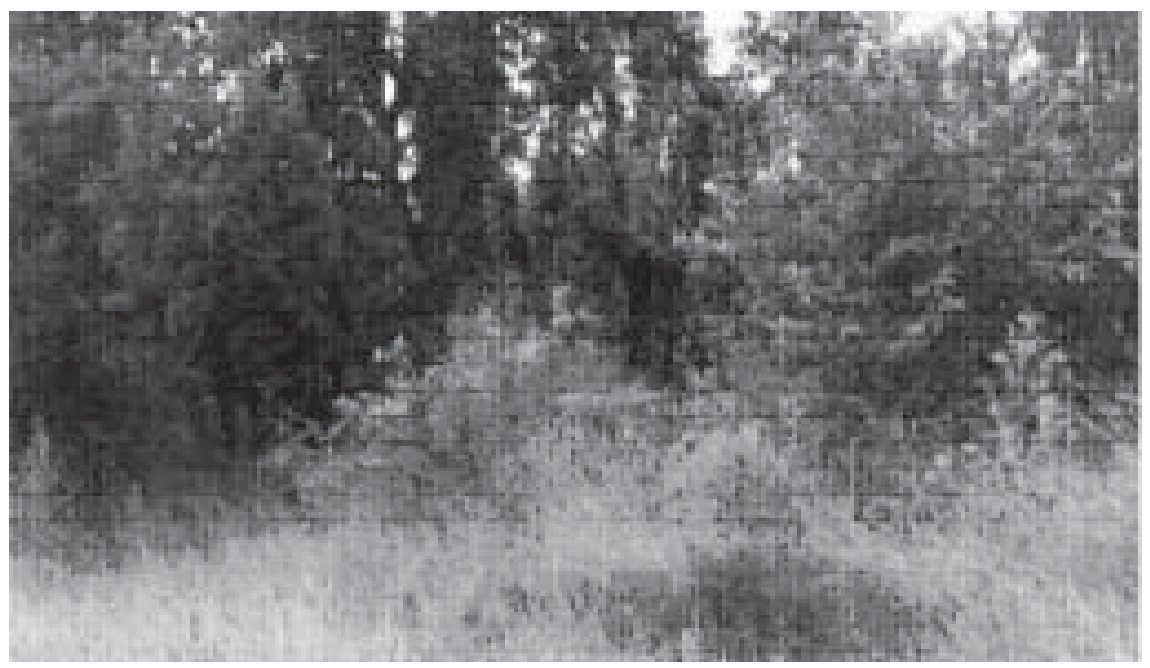

Figura 3 - Formação campestre - campo sujo - Fazenda Alegria. Silvânia - GO. - Hidasi, 2002.

Com o desmatamento e a expansão das cidades do interior do Estado observou-se aumento progressivo da casuística de leishmaniose tegumentar americana atendida em Goiânia, essencialmente no Hospital de Doenças Tropicais, hospital de referência para o tratamento dessa enfermidade (SUS-GO).

Até 1984 já haviam sido notificados um total de 565 casos autóctones nos municípios endêmicos, com um franco predomínio nos pacientes do sexo masculino e nos habitantes das zonas rurais próximas ou vizinhas às áreas com formações florestais.

A partir de 1997, por determinação da Secretaria Estadual de Saúde em Goiás, a notificação passou a ser pelo município de residência.

Assim, preocupa-nos a situação atual na região em relação ao conhecimento dessa doença e em especial ao controle do vetor e a falta de informação sobre o assunto. 
Devido ao fato de, repentinamente, municípios tradicionalmente não endêmicos notificarem casos novos, e visando ao conhecimento amplo da Leishmaniose Tegumentar Americana e a análise do recente aumento no número de notificações, justifica-se a necessidade da implementação de estudos bioecoepidemiológicos dessa doença.

\section{Referências}

HIDASI FILHO, J., GARCIA-ZAPATA, MTA., BATISTA, SRR., FREITAS, LZH. Estudo da L.T.A. em dois municípios goianos, Goiás, Brasil. Revista da Sociedade Brasileira de Medicina Tropical, 34 (supl. III): 70, 2001.

MASUTOMO, R., ASSAD, ED., RODRIGUEZ-CASTRO, LH., BARRETO, AJ., SILVA, FAM. Investigation and metereological analysis of geografical variation in the Brasilian cerrado area. In : EMBRAPA - CPAC ( org. ). Relatório do projeto nipo-brasileiro de cooperação em pesquisa agrícola nos cerrados, 1987/1992. Brasília, p 319-360. 1994.

MINISTÉRIODASAÚDE. Guia de controle da Leishmaniose Tegumentar Americana. Brasília: Fundação Nacional da Saúde, 2000. 62 p.

MONIZ, AC (Org.). Elementos de Pedologia. São Paulo: Editora da USP, 1972. 459 p.

PEREIRA, LIA. Leishmaniose Tegumentar estudo de um surto em Crixás, Goiás - Brasil ( agosto de 1974 ). Revista Patologia Tropical, Goiânia-GO, 10 (3): 181-191, 1981.

RIBEIRO, JF. \& WALTER, BMT. Fitofisionomias do bioma cerrado. In: Sano, SM. \& Almeida, SP. (Ed.). Cerrado. Ambiente e flora. Planaltina, Embrapa - CPAC, p 152189. 1998.

SAMPAIO, RNR \& de PAULA, CDR. Leishmaniose Tegumentar Americana no Distrito Federal. Revista da Sociedade Brasileira de Medicina Tropical, 32 (5): 523-528, 1999.

SANTOS, UG., HIDASI FILHO, J., GARCIA-ZAPATA, MTA. Evolução histórica sobre a presença de vetores responsáveis pela transmissão das leishmanioses humanas e métodos de captura no Estado de Goiás, Brasil (1914-2001). Revista da Sociedade Brasileira de Medicina Tropical, 34 (supl III), 69, 2001. 